\title{
Pós-escrito: Cabala e crítica em Umberto Eco
}

\author{
Bruno Loureiro Fernandes
}

Resumo

\begin{abstract}
Em O pêndulo de Foucault, Umberto Eco se utiliza da Cabala para a nomeação dos capítulos e de alguns personagens, bem como para a construção do enredo do romance. Pesquisando-se a bibliografia do romancista e professor, demonstrou-se possível a associação entre a fabulação e a teoria literária do italiano, através do conceito que se intitula semiose hermética.
\end{abstract}

Palavras-chave: O pêndulo de Foucault. Umberto Eco. Cabala. Semiose hermética. Semiótica.

A Cabalá, ou Cabala, pode ser definida como uma corrente do misticismo judaico que se baseia na idéia da criação do mundo como fenômeno lingüístico. Os textos cabalísticos são comentários sobre a Torá - a Lei, que equivale aos cinco primeiros livros do Antigo Testamento, tratada então como uma espécie de alfabeto com o qual o mundo teria sido construído (ECO, 1993). O cabalista reescreve a Torá, permutando suas letras através de técnicas que incluem anagramas, acrósticos e numerologia. Dessa forma, novos significados do texto sagrado são recriados ad infinitum, o que Harold Bloom descreve como "uma variante enlouquecida da liberdade de interpretação" (BLOOM, 1991, p. 56).

A Cabala foi uma heresia medieval e um método exegético de textos canônicos, dotados de uma significação ontológica para aqueles que lhe atribuíam valor de culto. Até os dias de hoje, essas crenças aparecem no ocidente em inúmeros almanaques e livros populares, misturadas à alquimia, à gnose, ao neoplatonismo, à astrologia, englobadas pelo que se denomina de "ciências ocultas", parte do movimento New Age.

Recentemente, o misticismo judeu se tornou modismo entre vários expoentes da indústria cultural norte-americana e, em conseqüência disso, recebeu enorme atenção da mídia, durante o processo desta pesquisa, que foi inspirada por uma passagem de Walter Benjamin, quando ele menciona que, "Se [...] compararmos a obra que cresce a uma fogueira ardente, o comentador se coloca diante dela como o químico, o crítico como o alquimista" (BENJAMIN, 2000, p. 275).

Constatou-se que tais metáforas poderiam ser relacionadas com uma influência do esoterismo nas obras do judeu-alemão, companheiro de infância de Gerschom Scholem - o fundador da pesquisa científica sobre a Cabala. O tema também aparece em escritos de Jorge Luís Borges, bem como na crítica literária de Harold Bloom. 
Faltava, entretanto, uma obra que pudesse evidenciar o próprio caráter literário da Cabala, ressaltar as possíveis relações entre o texto religioso e a obra artística, resumir todo o universo de analogias medievais e renascentistas, desleituras e releituras contemporâneas num mesmo corpus. Nada poderia ser mais adequado do que $O$ pêndulo de Foucault: a Cabala é uma das principais referências do romance em questão, sendo utilizada para a nomeação dos capítulos e personagens; desempenhando papel central no enredo do livro, que traz suspense e uma mistura muito particular de referências medievais, esotéricas e correlatas.

Embora as citações históricas e teológicas se apresentem em abundância neste trabalho do autor italiano, a narrativa é ambientada no século $X X$, mais especificamente em meados da década de 80. Dessa forma, poder-se-ia encontrar apenas um pastiche do crescimento da literatura esotérica na contemporaneidade.

Verificou-se, contudo, que $O$ pêndulo de Foucault poderia apresentar uma série de níveis de leitura - dependendo do conhecimento do leitor sobre a história da Cabala e os trabalhos acadêmicos publicados pelo romancista e professor. Haveria uma série de duplos-sentidos e ambigüidades no texto, algumas explícitas e outras subliminares. Um dos personagens principais do romance é um computador, Abulafia, nomeado em homenagem a um dos maiores cabalistas espanhóis, e encontrar-se-ia então um ensaio de Eco em que esse afirma, espirituosamente, que o sistema MS-DOS seria protestante; o Macintosh, católico. Declarou que "a linguagem de máquina [...] pertence ao Velho Testamento, e é talmúdica e cabalística" (ECO, 2005).

Com um autor tão irônico, que se utiliza do gótico e do românico como referências ao presente, a questão tornou-se definir qual a função narrativa da Cabala no romance. Eco trabalharia hermetismo como alusão à hermenêutica? Ou ainda: o Foucault do título é um cientista francês do século XIX - León Foucault, criador do pêndulo que demonstrou o movimento de rotação do planeta Terra. Seria possível encontrar aí uma alusão ao lingüista francês Michel Foucault?

Realizou-se então uma busca de indícios intertextuais e ecos cripto-sarcásticos, em tal corpus apocalíptico, eclético e integrado: um misto de romance histórico e policial, entre Borges e Sam Spade, os Cavaleiros Templários e o gênero noir. Para desemaranhar as tramas de tal textus caleidoscópico, efetivou-se uma leitura pendular do romance em questão sem, contudo, ter a pretensão de esgotar as possibilidades interpretativas de uma obra que, além de aberta, é "uma máquina de gerar interpretações".

Verificou-se, entretanto, que o próprio conceito de obra aberta propagado por Umberto Eco na década de sessenta vem sendo constantemente atualizado pelo semioticista. Em suas obras mais recentes, Eco defende que a crítica literária do século XX exagerou ao priorizar a intenção do leitor sobre o que ele chama de intentio operis, ou intenção do texto. De fato, verificou-se que mesmo seus primeiros escritos sobre a abertura de uma obra de arte pressupunham uma espécie de diálogo entre autor e leitor que, em sua opinião, foi esquecido pelos filósofos pós-estruturalistas. Assim, para o autor empírico de $O$ pêndulo de Foucault, existiria uma diferença entre uso e interpretação de uma determinada obra de arte. Interpretar significaria especular sobre uma suposta intenção do texto ou de um autor ideal, através de conjecturas ou, para usar a terminologia peirciana, abduções, que podem ou devem ser comprovadas por uma suposta coerência textual interna de um determinado objeto de estudo (ECO, 1995; ECO, 1997).

Trata-se de um tema polêmico nos estudos literários. Entretanto, as instruções do autor empírico do romance em questão definitivamente influenciaram a metodologia 
utilizada na pesquisa. Utilizou-se, principalmente, do método das passagens paralelas, através de comparações entre trechos da ficção de Eco e conceitos de suas obras sobre semiótica, procurando-se conexões entre os dois conteúdos. Trabalhou-se com o raciocínio hipotético-dedutivo, acompanhado de uma série de abduções.

Dessa forma, foi possível demonstrar a presença da mística judaica como elemento constitutivo de vários trabalhos de Umberto Eco sobre semiótica. A hermenêutica cabalista descrita no romance $O$ pêndulo de Foucault pode ser relacionada com trabalhos de Eco sobre semiótica, estabelecendo-se ficcionalmente um paralelo entre o misticismo medieval e a filosofia da linguagem hodierna.

Os passeios ficcionais pelos bosques de $O$ pêndulo de Foucault trouxeram questões sobre as inter-relações entre misticismo e ciência - que, embora estejam hoje separadas em compartimentos distintos do saber ocidental, se inspiraram mutuamente durante séculos. Verificou-se então a presença dessa mesma visão em outros trabalhos de Eco, como A busca da língua perfeita. Em seguida, observou-se como, em outras obras, o professor de Bolonha revela que suas teorias sobre os signos apresentam similaridades com o círculo hermenêutico (ECO, 1995), bem como se inspiram na hermenêutica teológica medieval de Santo Agostinho (ECO, 1989b, p. 214).

Enquanto isso, o romance descreve um raciocínio muito peculiar de seus protagonistas, descrito como hermético ou cabalista. Esses personagens criam um plano mirabolante, uma teoria da conspiração que é uma paródia explícita do texto anti-judaico Os protocolos dos sábios anciãos de Sion, um documento forjado na Rússia czarista, tido como verídico por grupos neonazistas até os dias de hoje (ROSENFELD, 1976). Jacopo Belbo Casaubon e Diotallevi vão simplesmente aglutinando fatos históricos em conexões pouco criteriosas, e podem então ser enxergados como um exemplo ficcional de um conceito semiológico criado paralelamente por Eco: a semiose hermética.

A semiose hermética foi o cerne do paralelo que se estabeleceu entre as heresias místicas e o pensamento filosófico de Eco. O pêndulo de Foucault pode ser lido como uma literalização irônica da semiose hermética (HUTCHEON, 2000): a deriva infinita, ou errância de significados, atribuída por Eco em um tom pejorativo àqueles que seriam adeptos da idéia de que não existem limites para a atribuição de significados a um determinado texto. O que o italiano também nomeia de "paradigma do velame" é a crença na inexistência de significados últimos e intenções autorais, ou de que esses seriam secretos ou inacessíveis a um leitor (ECO, 1995; ECO, 1997).

Ao criar esse conceito semiológico, fica evidente a preocupação de Eco em apontar limites, pautados pelo senso comum, além dos quais as inferências sobre um determinado conjunto de signos seriam equivocadas. Além da Cabala, a idéia de semiose hermética engloba textos da alquimia, da gnose, do neoplatonismo, as mnemotécnicas renascentistas e barrocas, algumas teorias filológicas e esotéricas consideradas delirantes. Toda essa lista de referências se encontra presente em sua obra sobre o pêndulo criado pelo físico Jean Bernard León Foucault.

No romance, a descrição desse experimento, que demonstrou a rotação do planeta Terra, enfatiza a existência de um ponto geométrico, fixo por não possuir dimensão. A partir dessa idéia de um centro fixo inexistente, a física do século XIX foi associada com o descentramento descrito pelo tipo de crítica pós-nietzscheana freqüentemente rotulada como pós-estruturalista, incluindo-se aí o homônimo Michel Foucault e o desconstrutor Jacques Derrida. A pertinência da atribuição de ironia intertextual à homonímia foucaulteana foi confirmada também por aquele conceito de 
semiose hermética, quando Eco acusa de alquímico ou cabalista boa parte do pensamento contemporâneo, com ênfase nas leituras desconstrutivas praticadas por seguidores de Derrida, um franco-argelino de origem judaica.

Maria Clara Castellões de Oliveira, a partir de trabalhos de Susan Handelman, também descreve Derrida e Bloom como "rabinos modernos ou hermeneutas heréticos" (OLIVEIRA, 2000, p. 35). Entretanto, embora o pensamento de Derrida possua influência de sua origem semita, a associação stricto sensu entre os discursos de um desconstrutor ateu e dos cabalistas medievais demonstrou-se frágil. Tal comparação poderia ser analisada como um artifício retórico de Eco, uma hipérbole teórica ou uma simples galhofa.

Não obstante, revelou-se pungente a incompatibilidade entre o italiano e Derrida, principalmente no que diz respeito às suas leituras divergentes do conceito peirciano de semiose ilimitada. Em sua defesa do raciocínio clássico do modus ponens contra as conjecturas "heréticas" de leitores incontinentes 'herméticos', o seguidor de Peirce e "grande admirador da poética aristotélica" (ECO, 1985, p. 49) parece revelar, mais uma vez, a veia metafísica e escolástica de sua teoria crítica.

Entre Eco e Bloom, essas diferenças já são mais conciliáveis. Se o primeiro ironiza e o segundo reverencia a mística judaica, ambos compartilhariam posições similares quando defendem o caráter literário do texto bíblico. Para Bloom, "religião é poesia derramada" (BLOOM, 1991, p. 62), pois "a distinção entre textos sagrados e seculares provém de decisões sociais e políticas e, portanto, não constitui uma distinção literária" (BLOOM \& ROSEMBERG, 1992, p. 23). A Cabala, entretanto, Ihe parece "única dentre os sistemas religiosos de interpretação, pelo fato de já ser simplesmente poesia" (BLOOM, 1991, p. 62). Ser um poeta forte é ser um Demiurgo, e todo novo poeta forte enxerga o Deus desconhecido da Cabala na angústia de ser influenciado por um predecessor. Seu conceito de desleitura é interpoético, quando todo poema desapropriaria e dialogaria defensivamente com um texto anterior. Como poetas, os cabalistas teriam confundido a substituição retórica com a magia. A Cabala, para ele, é a religião da literatura.

O best-seller com enredo de suspense, referências ao gênero noir e a personagens de histórias em quadrinhos e rituais de candomblé, num indiscutível hibridismo entre a cultura superior e o consumo de massa, possibilita também a leitura daquela idéia, comum a Bloom e Scholem, de que a magia dos cabalistas e poetas é na verdade um poder de significação - que pode criar mundos ficcionais, ou "bosques possíveis" (ECO, 2004) - através da simples combinação de letras do alfabeto.

Ao aproximar a arte de permutações cabalísticas de letras e números com a incipiente popularização dos computadores na década de 80 , O Pêndulo de Foucault transcende 0 suposto pós-moderno em direção a questões tipicamente contemporâneas, numa categoria cuja nomenclatura ainda não foi satisfatoriamente definida pela crítica. Na época do lançamento do romance, ainda não havia surgido a Internet, com sua gama de mundos virtuais criados pela linguagem de máquina, talvez ainda mais "parasitas do mundo real" (ECO, 2004) do que os universos ficcionais da literatura.

Contudo, assim como os textos cabalísticos nos quais se inspira, as significações do romance $O$ pêndulo de Foucault parecem transbordar as fronteiras interpretativas que o próprio autor estabelece em sua semiótica. Poder-se-ia definir o texto através da constatação de Ítalo Calvino sobre os grandes romances do século XX: tratar-se-ia de um hiper-romance onde se encontraria uma polifonia enciclopédica (CALVINO, 2003). Como romancista, Eco discorre com freqüência sobre labirintos e enciclopédias e 
acabou por construir um discurso labiríntico com sua enciclopédia invejável. Paralelamente, o professor de Bolonha se apropria da "pansemiótica cabalista" (ECO, 1993) medieval para construir uma visão irônica da semiótica hodierna. Ficção e teoria se entrelaçam.

Se o efeito poético já foi definido como "a capacidade que tem um texto de gerar leituras sempre diversas, sem nunca esgotar-se completamente" (ECO, 1985, p. 13), O pêndulo de Foucault é um exemplo de que, pelo menos em suas obras literárias, Umberto Eco continua promovendo a abertura total de sua obra às semioses ilimitadas de seus leitores - signos são lidos através de outros signos, numa espiral infinita. Com sua literatura, a obra de Eco abre espaço para infindáveis abduções, mesmo aquelas que, porventura, venham a ser definidas pelo autor italiano como "usos herméticos".

Abstract

In Foucault's Pendulum, the Kabbalah is used for naming its chapters, some characters and also plays an important role in the construction of the novel's plot. Research on Eco's bibliography has demonstrated a possible association between his novel and one of his theoretical concepts: hermetic semiosis.

Key words: Foulcault's Pendulum. Umberto Eco. Kabbalah. Hermetic semiosis. Semiotics.

Referências

BENJAMIN, Walter. Les affinités électives de Goethe: Oeuvres, Tome I. Paris: Gallimard, 2000.

BLOOM, Harold. Cabala e crítica. Rio de Janeiro: Imago, 1991.

BLOOM, Harold. Gênio. Os 100 autores mais criativos da história da literatura. Rio de Janeiro: Objetiva, 2003.

BLOOM, Harold; ROSEMBERG, David. O livro de J. Rio de Janeiro: Imago, 1992.

ECO, Umberto. A obra aberta. Forma e indeterminação nas poéticas contemporâneas. São Paulo: Perspectiva, 1971.

ECO, Umberto. Interpretação e superinterpretação. São Paulo:

Martins Fontes, 1997.

ECO, Umberto. Kant e o ornitorrinco. Rio de Janeiro: Record, 1998.

ECO, Umberto. La Búsqueda de la lengua perfecta. Barcelona: La construcción de Europa/Critica, 1993.

ECO, Umberto. O pêndulo de Foucault. Rio de Janeiro: Record, 1989.

ECO, Umberto. Os limites da interpretação. São Paulo: Perspectiva, 1995. 
ECO, Umberto. Pós-escrito a O nome da rosa. Rio de Janeiro: Nova Fronteira, 1985.

ECO, Umberto. The holy war. MAC vs. DOS. Disponível no endereço: www.themodernworld.com/eco/eco/mac_vs_pc. html. Acesso 29 mar 2005.

ECO, Umberto. Sobre os espelhos e outros ensaios. Rio de Janeiro: Nova Fronteira, 1989b.

ECO, Umberto. Seis passeios pelo bosque da ficção. São Paulo: Companhia das Letras, 2004.

FERNANDES, Bruno Loureiro. O código de Eco. Estado de Minas. Caderno Pensar, 23 de abril de 2005.

HUTCHEON, Linda. Teoria e política da ironia. Belo Horizonte: UFMG, 2000.

OLIVEIRA, Maria Clara Castellões. O pensamento tradutório judaico: Franz Rosenweig em diálogo com Benjamin, Derrida e Haroldo de Campos. 2000. Tese (Doutorado em Estudos Literários) - Faculdade de Letras, Universidade Federal de Minas Gerais, 2000.

PEIRCE, Charles Saunders. Semiótica. São Paulo: Perspectiva, 1977.

ROSENFELD, Anatol. Mistificações literárias: Os Protocolos dos sábios anciãos de Sião. São Paulo: Perspectiva, 1976.

SCHOLEM, Gerschom. A Cabala e seu simbolismo. São Paulo: Perspectiva, 1988

SCHOLEM, Gerschom. A mística judaica. São Paulo: Perspectiva, 1972. 